\title{
Effect of moisture content, lactic acid addition and extrusion conditions on reduction of $\beta$-aflatoxins in milled sorghum (Sorghum L. Moench)
}

\author{
A. Méndez-Albores ${ }^{1,4}$, F. Martínez-Bustos ${ }^{2}$, J. Véles-Medina ${ }^{2}$, \\ E. Castaño-Tostado ${ }^{3}$ and E. Moreno-Martínez ${ }^{1}$ \\ ${ }^{1}$ UNAM -FESC. Av. J. Jiménez Cantú S/N, Col. Atlamica \\ Cuautitlán Izcalli, C.P. 57740, México \\ ${ }^{2}$ CINVESTAV-IPN \\ Apartado postal 1-798, C. P. 76230, Querétaro-México \\ ${ }^{3}$ DIPA-Autonomous University of Queretaro \\ Cerro de las Campanas, S/N C.P. 76010, Querétaro, México
}

(Received 11 June 2007; revised version 16 May 2008; accepted 24 June 2008)

\begin{abstract}
Sorghum flour contaminated with $\beta$-aflatoxins at a level of $140 \pm 7.34 \mathrm{ng} / \mathrm{g}$ was extrusion-cooked in a single screw extruder under two different conditions: moderate (ME) and severe (SE). The difference in the processing conditions was in the temperature profile of the barrel sections of the extruder: $60-80-100^{\circ} \mathrm{C}$ for $\mathrm{ME}$ and $80-150-200^{\circ} \mathrm{C}$ for SE, respectively. The flour moisture content (MC) was adjusted at 20,25 and $30 \%$ by means of aqueous lactic acid (LA) at concentrations of 0 , $0.5,1.0,2.0,4.0$ and $8.0 \mathrm{~N}$. The effect of the three extrusion variables (temperature profile, $\mathrm{MC}$ and LA concentration) was analysed as a completely randomized factorial design $2 \times 3 \times 6$. The barrel temperature profile, in combination with the MC and LA concentration, significantly affected the extent of aflatoxin reduction in the extruded sorghum. The recovered aflatoxin decreased with an increase in $\mathrm{MC}$ and LA concentration, in both temperature-profiles evaluated. The SE condition produced higher aflatoxin degradation rates (from 16.38 to $67.09 \%$ ) than the ME condition (up to $19.79 \%)$.
\end{abstract}

KEY WORDS: sorghum, $\beta$-aflatoxins, lactic acid, extrusion-cooking, detoxification

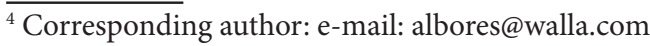




\section{INTRODUCTION}

Contamination of agricultural commodities with mycotoxins presents a serious hazard for human and animal health. Many countries have, therefore, established measures to control the contamination by mycotoxins of food and feedstuffs (EU, 2006).

The enforcement of legal limits for mycotoxins in animal feed is important for the health protection of potential consumer of any edible animal product which may be contaminated with mycotoxins, as well as for protection against economical losses due to the adverse effects exerted by some mycotoxins on animal productivity, such as in the production of meat, milk and eggs.

The Food and Agriculture Organization (FAO) estimates that at least 25\% of world cereal production is contaminated with mycotoxins (Dowling, 1997). For this reason, development of detoxification procedures are needed. Such detoxification procedures should not only reduce the concentration of toxins to "safe" levels (below regulatory limits), but also prevent production of toxic degradation products and non-reduction of the nutritional value of the treated commodities. A number of approaches have been tried in an attempt to detoxify aflatoxins; however, only a few have yielded practical applications. Among these, ammoniation has proven to be an effective and cost-efficient means for reducing the aflatoxin content in peanut meal, maize and cottonseed destined for animal feeding (Marth and Doyle, 1979).

Reductions in mycotoxin levels, microbial contamination, and other toxic substances (such as trypsin inhibitors) are achieved during the cooking, particularly in the extrusion-cooking (Cazzaniga et al., 2001; Buser and Abbas, 2002; Castells et al., 2005). High temperature/short time extrusion-cooking methods are used in the industry to produce expanded products such as snack foods, breakfast cereals and pet foods (Rahman, 1995). Results for these methods have proven to be favourable for detoxification.

Also, organic acids have shown in previous studies to perform a detoxification function in treating aflatoxin-contaminated food/feeds (Méndez-Albores et al., 2005 , 2007). These results suggest that detoxification of aflatoxin $B_{1}\left(A_{F} B_{1}\right)$ initially involves the formation of the $\beta$-keto acid structure (catalysed by the acidic medium), followed by hydrolysis of the lactone ring yielding aflatoxin $\mathrm{D}_{1}\left(\mathrm{AFD}_{1}\right)$, derived from decarboxylation of the lactone ring-opened form of $\mathrm{AFB}_{1}$, which is 450 times less mutagenic than $\mathrm{AFB}_{1}$ and presents an 18-fold toxicity decrease. Since no information has been available concerning the use of lactic acid during the extrusion-cooking of aflatoxin-contaminated sorghum, the purpose of the present study was to determine the effect of moisture content, addition of lactic acid, and various processing conditions (temperature profiles) on the stability 
of $\beta$-aflatoxins, in an attempt to validate practical detoxification procedures for large-scale application.

\section{EXPERIMENTAL}

Experimental units (EU) of sorghum flour contaminated with $\beta$-aflatoxins $(140 \pm 7.34 \mathrm{ng} / \mathrm{g})$ were extrusion-cooked under two temperature profiles, three different moisture contents (MC), and six lactic acid (LA) concentrations. The effect of these extrusion variables was analysed as a completely randomized factorial design $2 \times 3 \times 6$ with two replicates. The first factor corresponded to the extrusion-cooking conditions (ME and SE), the second to the sample MC (20, 25 and 30\%), and the third to the aqueous LA concentration $(0,0.5,1.0,2.0,4.0$ and $8.0 \mathrm{~N})$.

Chemicals such as $\beta$-aflatoxins and LA (85\% purity) were obtained from Sigma Chemical Co. Ltd. (St Louis, MO, USA). Other analytical chemicals were obtained from J.T. Baker Mexico (Plomo 2, Industrial Xalostoc, México).

Procedures used for handling contaminated AFB materials were adopted from recommendations published by the International Agency for Research on Cancer (Castegnaro et al., 1981)

Sorghum grain of the commercial variety RB-3030 was utilized, with initial MC of 9.7 and $65 \%$ of seeds invaded by Fusarium verticilliodes. Moisture content was determined by drying replicate portions of 5-10 $\mathrm{g}$ each of whole grain at $103^{\circ} \mathrm{C}$ for $72 \mathrm{~h}$, with percentages calculated on a wet-weight basis. The grain was aflatoxin-free, as tested with the AOAC (1995) immunoaffinity column method described below.

The fungus Aspergillus flavus originally isolated from aflatoxin-contaminated maize, UNIGRAS-1231 (Culture Collection of the Grain and Seed Research Unit of the National Autonomous University of Mexico) was inoculated into Petri dishes containing MSA medium (\%: malt extract, 2; sodium chloride, 6; and agar, 2) for 7 days at $25^{\circ} \mathrm{C}$. This strain UNIGRAS- 1231 is only capable of producing $\mathrm{AFB}_{2}$ and $\mathrm{AFB}_{1}$. In order to inoculate the sorghum grain, the fungal spores were removed from the Petri dishes with a spatula; a sterile-water spore suspension (5.8 1) was prepared with approximately 100,000 conidia/ml, and this suspension was used to elevate the $\mathrm{MC}$ of the grain. This amount of inoculum $(\approx 10,500$ spores/g of sorghum) was determined in order to eliminate competition with other storage fungi which could potentially grow under such incubation moisture and temperature conditions.

The total amount of sorghum to be inoculated was $55 \mathrm{~kg}$. The $\mathrm{MC}$ of the grain was adjusted to $18 \%$ and stored in plastic bottles (5 $\mathrm{kg}$ of sorghum per replicate). Bottles were covered with thin polyethylene film to minimize the loss of humidity 
from the grain. However, ten perforations with a pin were made to each film to avoid the accumulation of carbon dioxide generated by the respiration of grains and fungi. Bottles were incubated at $27^{\circ} \mathrm{C}$ during $24 \mathrm{~d}$. After the incubation period, the grain was put under a $1000 \mathrm{mg} / \mathrm{l}$ ethylene oxide gas atmosphere for $5 \mathrm{~h}$, to stop further development of the toxigenic fungus and to avoid the dispersal of viable spores. Finally, the aflatoxin-contaminated grain was finely ground in a mill (Pulvex-200, Pulvex, S.A. de C.V. Plutarco Calles 290, Mexico, DF), dried to $11.5 \% \mathrm{MC}$, and transferred to clean plastic bags, labeled, and stored at $4^{\circ} \mathrm{C}$ to await aflatoxin analysis.

The aflatoxin content was determined according to the 991.31 AOAC (1995) method, using monoclonal antibody columns for aflatoxins $B_{2}$ and $B_{1}$ (VICAM Science Technology, 303 Pleasant St., Watertown, MA, USA). When the concentration of total aflatoxins was greater than $25 \mathrm{ng} / \mathrm{g}$, dilutions from the extract were made for their quantification in the fluorometer after reaction with a bromine solution at $0.002 \%$ (Candlish et al., 1991). The detection limit for aflatoxins with the immunoaffinity column (IAC) via fluorescence measurement is approximately 0.5 $\mathrm{ng} / \mathrm{g}$ (Hansen, 1990). Aflatoxin identification was carried out by means of a Waters HPLC equipment with two pumps (Mod 510. Waters Associates, Milford, MA) and a Waters Nova-Pak C18, reverse phase column $(5 \mu \mathrm{m}, 3.9 \times 150 \mathrm{~mm})$. Standards as well as samples collected from the IAC $(20 \mu 1)$, were injected into an HPLC and eluted isocratically with a mobile phase of $12.5 \mathrm{mN}$ acetic acid:acetonitrile $(1: 1, \mathrm{v} / \mathrm{v})$ at a flow rate of $1 \mathrm{ml} / \mathrm{min}$. Aflatoxins were fluorometrically detected and identified using a fluorescence detector Waters 470AC; the excitation and emission wavelengths were 338 and $425 \mathrm{~nm}$, respectively. Aflatoxins were identified by their retention time (Rt), and compared with those for a pure aflatoxin standard solution under identical conditions. The performance of the 991.31 AOAC (1995) method was tested by the percentage of aflatoxin recovery by means of the HPLC method.

The MC of each EU consisting of $700 \mathrm{~g}$ milled sorghum was adjusted to 20, 25 or $30 \%$ by adding $78.1,132.3$ or $194.2 \mathrm{ml}$ of aqueous LA solution at $0,0.5,1.0$, $2.0,4.0$ or $8.0 \mathrm{~N}$ (the range of LA expressed in percentage was from 0.5 to $20 \%$ ). Samples were mixed at low speed for $15 \mathrm{~min}$ in a mixer (model C-100, Hobart Corp., Troy, OH). After mixing, samples were transferred to plastic bags and stored at $4^{\circ} \mathrm{C}$ for $72 \mathrm{~h}$, in order to achieve MC equilibration (after which period, MC was determined). The total number of EU was 72 (36 for each extrusioncooking condition).The $\mathrm{pH}$ of the milled sorghum and extrudates was determined according to the 02-52 AACC method (2000).

A laboratory scale single screw extruder was used, designed and manufactured by CINVESTAV-IPN, Mexico with a barrel diameter of $2.5 \mathrm{~cm}$, length of $42.8 \mathrm{~cm}$, screw compression ratio of 1:1, and a 3-mm diameter cylindrical die. The barrel was equipped with electrical cartridge heaters and three independently controlled heating 
and cooling zones. The feed rate of $16 \mathrm{rpm}(73 \mathrm{~g} / \mathrm{min})$ and the screw speed of $30 \mathrm{rpm}$ were constant throughout the experiment. The difference in the processing conditions was in the temperature profile in the barrel sections: $60-80-100^{\circ} \mathrm{C}$ for the $\mathrm{ME}$ condition, and $80-150-200^{\circ} \mathrm{C}$ for the $\mathrm{SE}$ condition. The range of temperature fluctuation in each zone was approximately $\pm 2{ }^{\circ} \mathrm{C}$. The extruder was not stopped or cleaned between samples; therefore, a portion of the next test material was used to purge the extruder. Each EU was run through the extruder, and approximately $500 \mathrm{~g}$ of extrudate sample was collected after achieving steady-state flow in the extruder. Extruded samples were oven-dried at $40^{\circ} \mathrm{C}$ for $24 \mathrm{~h}$ and stored at $4^{\circ} \mathrm{C}$ until analysed.

Analysis of variance (ANOVA) was used to evaluate the effect of temperature profile, moisture content and lactic acid concentration. Means were separated by the Tukey procedure using the Statistical Analysis System (SAS, 1998).

\section{RESULTS AND DISCUSSION}

The total $\beta$-aflatoxins concentration in the inoculated sorghum was $140 \pm 7.34 \mathrm{ng} / \mathrm{g}$. This aflatoxin concentration is not commonly found in the commercial sorghum used to produce foods or feeds. The idea was to use it to test the potential detoxifying activity of LA under these specific conditions of extrusion. The chromatograms of the HPLC (not presented) indicated that the toxins in the sorghum flour were $\mathrm{AFB}_{2}$ and $\mathrm{AFB}_{1}$, with concentrations of 11.2 and $128.8 \mathrm{ng} / \mathrm{g}$, respectively. It has been stated that $A$. flavus produces mainly $\beta$-toxins (De Arriola et al., 1988). The HPLC chromatograms, however, indicate that clear separation of aflatoxins occurred; the Rt values for $\mathrm{AFB}_{2}$ and $\mathrm{AFB}_{1}$ standards were 3.7 and $4.0 \mathrm{~min}$, respectively.

Table 1 shows the MC of the sorghum flour before extrusion-cooking: $19.89 \pm 0.05,25.12 \pm 0.08,30.29 \pm 0.07 \%$ for samples to be processed with ME conditions, and $20.39 \pm 0.17,25.30 \pm 0.22,30.30 \pm 0.12 \%$ for samples to be processed with SE conditions. Consequently, the $\mathrm{MC}$ of all EU was considered to have been stable throughout the equilibrating period $\left(72 \mathrm{~h}\right.$ at $\left.4^{\circ} \mathrm{C}\right)$.

In general, extrusion caused MC reductions around $29.94 \pm 4.07 \%$ and $67.50 \pm 2.68 \%$, in samples processed under conditions ME and SE, respectively (Table 1). These reductions in $\mathrm{MC}$ are attributable to the differences in temperature profiles under both extrusion conditions. Statistical differences in $\mathrm{pH}$ (Table 1) were not observed before or after the extrusion-cooking of the samples under both conditions evaluated. The $\mathrm{pH}$ levels of the adjusted sorghum flour (data not presented) were essentially the same as those registered for extrudates. As LA concentration and MC increased, lower $\mathrm{pH}$ values were observed. Samples with no acid (control) presented an average $\mathrm{pH}$ value of 6.10 ; while the lowest $\mathrm{pH}$ value of near 3.46 was observed in samples processed with 30\% MC and $8.0 \mathrm{~N}$ LA (Table 1). 


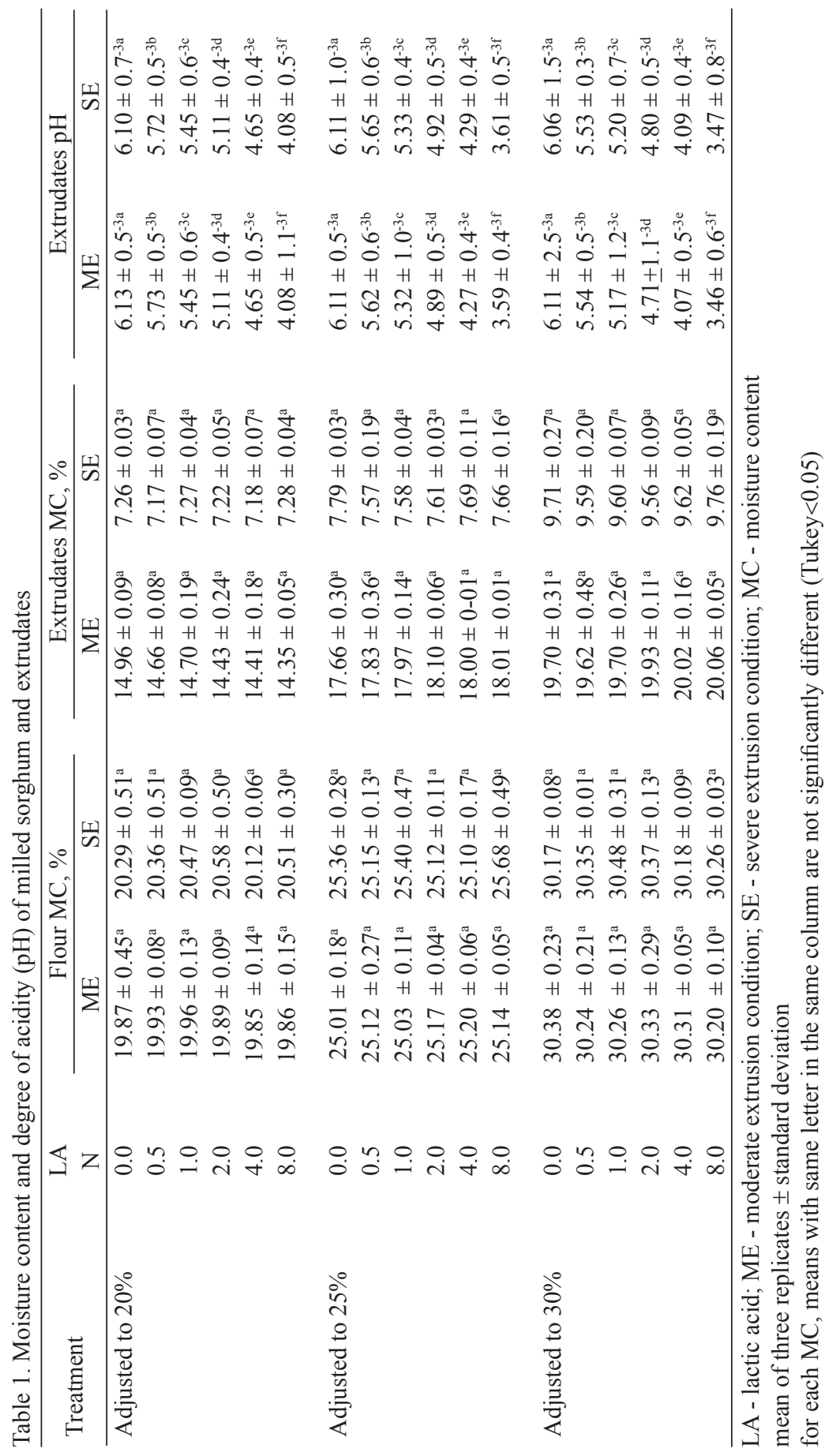


Different levels of LA (50 and $100 \mathrm{~g} / \mathrm{kg}$ dry matter) added to silage for dairy cows (a mixture of barley and soyabean meal, 75:25) were investigated to evaluate the effect of LA on silage intake and milk production, with and without a post-ruminal supplement of $230 \mathrm{~g} / \mathrm{d}$ sodium caseinate (Choung and Chamberlain, 1993). Both levels of LA added ultimately reduced the intake of silage, and milk yield was reduced only with the addition of $100 \mathrm{~g} \mathrm{LA}$; however, this effect was reversed when casein was administered post-ruminally. In all treatments, casein infusion increased the yield of protein in milk by $30-35 \mathrm{~g} / \mathrm{d}$, and protein concentration in milk was also increased linearly with the addition of LA to the silage. In this research, it is possible that similar beneficial as well as detrimental effects occur in relation to high doses of LA added to sorghum. In relation to those doses of LA used in the present research, they were in the range of 0.5 to $20 \%$. Doses higher than $10 \%$ should be tested for possible detrimental effects in feed for different species of animals. Dilution of acid treated raw materials could be another way to reduce the noxious effects of these ingredients in feed.

The stability of $\beta$-aflatoxins in the sorghum was significantly affected by the extrusion-cooking parameters (temperature profile, sample $\mathrm{MC}$, and LA concentration) in both conditions evaluated (Figure 1). The amount of $\beta$-aflatoxins decreased, as MC and LA concentration increased. The highest reduction in the aflatoxin content $(67.09 \%)$ was observed in the case of extrudates obtained under conditions of SE at 30\% MC and $8.0 \mathrm{~N} \mathrm{LA}$. In these samples, the final aflatoxin content was $46.06 \pm 1.22 \mathrm{ng} / \mathrm{g}$ (Figure 1, profile a). However, only a $19.79 \%$ aflatoxin reduction occurred during the extrusion-cooking by means of ME conditions in samples extruded with $30 \% \mathrm{MC}$ and $8.0 \mathrm{~N} \mathrm{LA}$; these samples, had a final aflatoxin content of $112.33 \pm 1.97 \mathrm{ng} / \mathrm{g}$ (Figure 1, profile b).

In samples without the addition of LA (controls) and processed under ME conditions, there was no apparent reduction in the aflatoxin content; however, when controls were processed under conditions of SE, a $24.95 \%$ reduction in the aflatoxin content was observed (Figure 1).This reduction may possibly be due to the combined action of $\mathrm{MC}$ and a higher temperature profile in SE condition. Under these conditions (SE), sorghum was processed with high temperature/ pressure combined with severe mechanical shear stress, which resulted in a moderate reduction in the aflatoxin content without additive addition (LA). It is well known that aflatoxins are relatively heat-stable and are not completely destroyed when thermally treated to produce food or feeds. $\beta$-Toxins have been found to be unstable up to their melting points of around $250^{\circ} \mathrm{C}$ (Feuell, 1966).

In this type of experimental extruder, the product resides in the barrel for $59 \mathrm{sec}$, with consequent moderate reductions of $\beta$-aflatoxins observed. Previous studies indicate that higher temperatures and longer times are required to significantly reduce the levels of aflatoxins during food processing (Samarajeewa et al., 1990). 

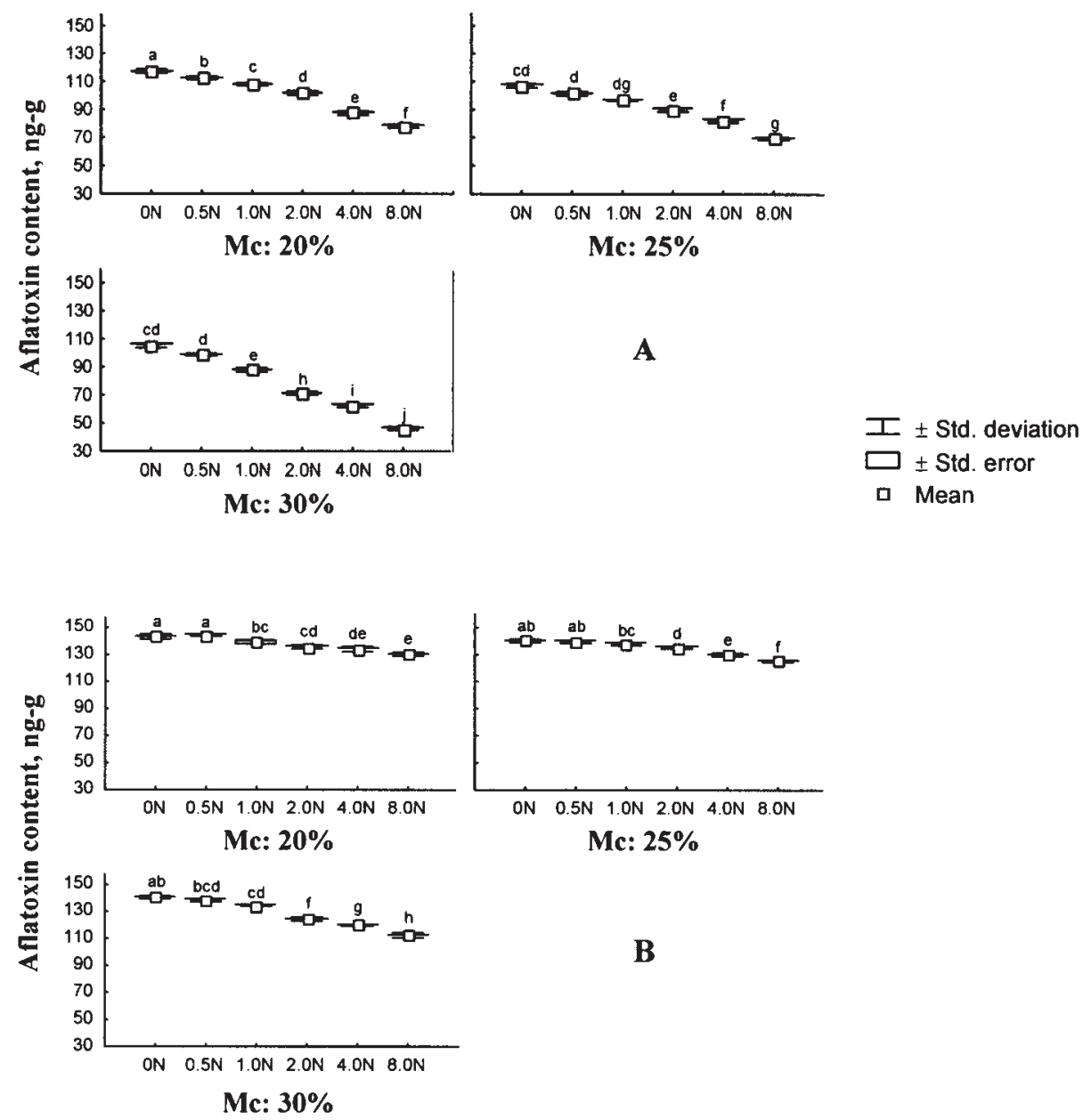

Figure 1. Lactic acid effect on aflatoxin reduction during extrusion of contaminated sorghum with different temperature profiles: A - severe, B - moderate

* for each temperature profile, box and whiskers with same letter are not significantly different (Tukey<0.05)

Castells et al. (2005) reported that the extrusion of rice flour contaminated with $\mathrm{AFB}_{1}, \mathrm{AFB}_{2}, \mathrm{AFG}_{1}$ and $\mathrm{AFG} 2$, reduced the levels by 51 to $95 \%$, depending on the type of aflatoxin and variables studied such as MC, barrel temperature, and residence time. The same authors reported reductions of 100,95 , and $83 \%$ for fumonisins, aflatoxins, and zearalenone, during extrusion-cooking of cereals, and lower reductions for deoxynivalenol, ochratoxin A and moniliformin, where toxin reductions did not exceed 55,40 and $30 \%$, respectively. 
Saalia and Phillips (2002) reported that the extent of aflatoxin detoxification during the extrusion of yellow maize with high levels of spiked aflatoxins (150 $\mathrm{ng} / \mathrm{g}$ for $\mathrm{AFB}_{1}$ and $\mathrm{AFG}_{1}$, and $45 \mathrm{ng} / \mathrm{g}$ for $\mathrm{AFB}_{2}$ and $\mathrm{AFG}_{2}$ ) was dependent on the temperature, $\mathrm{MC}, \mathrm{pH}$, and nucleophile addition. With a residence time of 85 sec, the best conditions for aflatoxin reduction were treatments at $35 \% \mathrm{MC}$ and $\mathrm{pH} 9$, with or without lysine addition. Under these conditions, $62 \%$ reduction in the content of total aflatoxins was achieved. The same authors reported that $\mathrm{pH}$ showed significant aflatoxin reduction, even without heating. Cazzaniga et al. (2001) reported that extrusion of maize flour at low levels of $\mathrm{AFB}_{1}(50 \mathrm{ng} / \mathrm{g})$, was partially successful (10-25\%) for the decontamination with metabisulphite addition $(1 \%)$ at temperatures of 150 and $180^{\circ} \mathrm{C}$, respectively. In the case of aflatoxin contaminated cottonseed (339 $\mathrm{ng} / \mathrm{g} \mathrm{AFB}_{1}$ ), reductions of 46 and $65 \%$ were observed, when samples were extrusion-cooked at 104 and $160^{\circ} \mathrm{C}$, respectively. Furthermore, multiple-pass extrusion produced an additional $55 \%$ of aflatoxin reduction when cottonseed was extruded four times as compared to one time (Buser and Abbas, 2002).

In relation to the above cited aflatoxin reductions, it is noted that the detoxification of contaminated materials varies considerably, depending on the extrusion processing parameters, such as: screw configuration, feed moisture content, temperature profile in the barrel sections, screw speed, feed rate, final die configuration, initial aflatoxin concentration and the use of additives. It is important to note that the type of extruder also could have a significant impact on the residence time, the degree of mixing and internal pressure and that this factor could alter the performance of the equipment used to detoxify the extruded materials.

\section{CONCLUSIONS}

Extrusion-cooking temperature, moisture content (MC) as well as lactic acid (LA) concentration, significantly affected the stability of $\beta$-aflatoxins in the milled sorghum. Lower levels of $\beta$-aflatoxins $(46.06 \mathrm{ng} / \mathrm{g}$ ) were found in samples processed with the higher temperature profile, coupled with the highest $\mathrm{MC}$ and LA concentration. Assuming that similar extrusion-cooking conditions could be used for the production of feeds, reductions of about $67.09 \%$ in $\beta$-aflatoxins levels can be expected. The results suggest that more severe extrusion conditions with respect to these three variables (temperature, MC, and LA concentration) are required to obtain higher detoxification rates of $\beta$-aflatoxins in the contaminated sorghum. 


\section{ACKNOWLEDGEMENTS}

The authors are grateful to DGAPA/UNAM for the first author postdoctoral fellowship. We wish to thank Elisabeth Buchanan for her English revision.

\section{REFERENCES}

AACC International, 2000. Approved Methods of the American Association of Cereal Chemists. 10th Edition. Method 02-52. The Association: St. Paul, MN

AOAC, 1995. Association of Official Analytical Chemists, Official Methods of Analysis. 16th Edition. Method 991.31. Gaithersburg, MD

Buser M.D., Abbas H.K., 2002. Effects of extrusion temperature and dwell time on aflatoxin levels in cottonseed. J. Agr. Food Chem. 50, 2556-2559

Candlish A.A., Harran G., Smith J.E., 1991. Immunoaffinity column chromatography for detection of total aflatoxins in experimental situations. Biotechnol. Technique. 5, 317-322

Castegnaro M., Hunt D.C., Sansone E.B., Schuller P.L., Siriwardana M.G., Telling G.M., van Egmond H.P., Walter E.A., 1981. Laboratory decontamination and destruction of aflatoxins $\mathrm{B}_{1}$, $B_{2}, G_{1}, G_{2}$ in laboratory wastes. IARC Monograph. 37, 1-59

Castells M., Marin S., Sanchis V., Ramos A.J., 2005. Fate of mycotoxins in cereals during extrusion cooking: a review. Food Addit. Contam. 22, 150-157

Cazzaniga D., Basílico J.C., González R.J., Torres R.L., de Greef D.M., 2001. Mycotoxins inactivation by extrusion cooking of corn flour. Lett. Appl. Microbiol. 33, 144-147

Choung J.J., Chamberlain D.G., 1993. Effects of addition of lactic acid and post-ruminal supplementation with casein on the nutritional value of grass silage for milk production in dairy cows. Grass Forage Sci. 48, 380-386

De Arriola M., de Porres E., de Cabrera S., de Zepeda M., Rolz C., 1988. Aflatoxin fate during alkaline cooking of corn for tortilla preparation. J. Agr. Food Chem. 36, 530-553

Dowling T.S., 1997. Fumonisins and its toxic effects. Cereal Food. World 42,13-15

EU, 2006. Commission Regulation (EC) No1881/2006 setting maximum levels for certain contaminants in feedstuffs. Off. J. Eur. Union. No. L 364/15-18

Feuell A.J., 1966. Aflatoxin in groundnuts. IV. Problems of detoxification. Trop. Sci. 8, 61

Hansen J.T., 1990. Affinity column clean-up and direct fluorescence measurement of aflatoxin $M_{1}$ in raw milk. J. Food Protect. 53, 75-77

Marth E.H., Doyle M.P., 1979. Update on molds: degradation of aflatoxin. Food Technol. 33, 81

Méndez-Albores A., Arámbula-Villa G., Loarca-Piña M.G.F., Castaño-Tostado E., Moreno-Martínez E., 2005. Safety and efficacy evaluation of aqueous citric acid to degrade B-aflatoxins in maize. Food Chem. Toxicol. 43, 233-238

Méndez-Albores A., Del Río-García J.C., Moreno-Martínez E., 2007. Decontamination of aflatoxin duckling feed with aqueous citric acid treatment. Anim. Feed Sci. Tech. 135, 249-262

Rahman S., 1995. Food Properties Handbook. CRC Press, New York

Samarajeewa U., Sen A.C., Cohen M.D., Wei C., 1990. Detoxification of aflatoxin in food and feeds by physical and chemical methods. J. Food Protect. 56, 489-501

Saalia F.K., Phillips R.D., 2002. Reduction of aflatoxins in contaminated corn by extrusion cooking. In: Annual Meeting Inst. Food Technology. Anaheim, CA. Book of Abstracts, p. 115

SAS, 1998. Introductory Guide for Personal Computers. SAS Institute. 6.12 Edition. Cary, NC 